\title{
Seroprevalence of coxsackievirus A16 antibody among people of various age groups: a systematic review and meta-analysis
}

Peng Li $i^{1} \mathbb{D}$, Yan Chen ${ }^{1}$, An Tang ${ }^{1}$, Fan Gao ${ }^{2^{*}}$ and Jian-Bo Yan ${ }^{1 *}$

\begin{abstract}
Background: Coxsackie virus group A type 16 (CoxA16) is the main pathogen and usually an alternative to or joins in prevalence with enterovirus 71 (EV71) causing hand, foot and mouth disease (HFMD). The objective of this study was to estimate the seroprevalence of CoxA16 antibody among people of various age groups by a systematic review and meta-analysis.
\end{abstract}

Methods: The literature of seroprevalence of CoxA16 antibody among people has been systematically searched through databases from the date of their establishment to Jan. 2021. Estimates of seroprevalence of CoxA16 antibody by gender and age groups have been summarized by using fixed- and random- effect models. All analyses have been conducted in STATA version 12.0 software.

Results: A total of 14 publications with 9 in English and 5 in Chinese containing 9562 samples were finally included in the meta-analysis. The seroprevalence of CoxA16 antibody reported in different studies range from 24.85 to $76.92 \%$. Meta-analysis has revealed that the seroprevalence of CoxA16 antibody was $56.3 \%$ (95 \%Cl: $47.7 \%$ 64.9\%) in the overall population and $55.1 \%(95 \% \mathrm{Cl}$ : $44.1 \% \sim 66.1 \%)$ in the Chinese population. Subgroup analysis by gender has revealed that the seroprevalence of CoxA16 antibody was $56.1 \%$ (95\%Cl: 45.2\% 67.1\%) in males and $60.0 \%$ (95 \% Cl: $50.0 \%$ 69.9\%) in females. Subgroup analysis by age groups has revealed that the seroprevalence of CoxA16 antibody was $49.1 \%$ (95\%Cl: 36.2\% 62.0\%) in the $0 \sim 5$ age group and $63.9 \%$ (95 \%Cl: $53.1 \% \sim 74.7 \%)$ in the over 5 age group. Begg's funnel plots have suggested that there were no publication bias in all groups. Sensitive analysis has suggested that the result of the meta-analysis was stable.

Conclusions: The seroprevalence of CoxA16 antibody was closely related to age. Children under 5 years old were the main susceptible groups for CoxA16 and also the key groups for the prevention and control of HFMD.

Keywords: Seroprevalence, Coxsackievirus A16, Hand, foot and mouth disease(HFMD), Meta-analysis

\footnotetext{
* Correspondence: xinran-83-08-18@163.com; yanjianbo02@163.com

2Department of Ophthalmology, Zhoushan Hospital, Zhoushan City, Zhejiang Province 316021, People's Republic of China

'Zhoushan Municipal Center for Disease Control and Prevention, No.568 Wengshan Road, Zhoushan City, Zhejiang Province 316021, People's Republic of China
}

C C The Author(s). 2021 Open Access This article is licensed under a Creative Commons Attribution 4.0 International License, which permits use, sharing, adaptation, distribution and reproduction in any medium or format, as long as you give appropriate credit to the original author(s) and the source, provide a link to the Creative Commons licence, and indicate if changes were made. The images or other third party material in this article are included in the article's Creative Commons licence, unless indicated otherwise in a credit line to the material. If material is not included in the article's Creative Commons licence and your intended use is not permitted by statutory regulation or exceeds the permitted use, you will need to obtain permission directly from the copyright holder. To view a copy of this licence, visit http://creativecommons.org/licenses/by/4.0/. The Creative Commons Public Domain Dedication waiver (http://creativecommons.org/publicdomain/zero/1.0/) applies to the data made available in this article, unless otherwise stated in a credit line to the data. 


\section{Background}

HFMD, an infectious disease caused by enterovirus, is common in children under 5 years of age, with the highest morbidity and mortality among children aged from 12 to 23 months [1, 2]. HFMD can cause fever, rashes and ulcers on hands, foot, and mouth. A small number of patients may develop neurological and cardiopulmonary complications such as aseptic meningitis, brainstem encephalitis, acute flaccid paralysis, pulmonary edema, and cerebral hemorrhage, or even death [3]. Viruses causing HFMD belong to the enterovirus family of the small RNA family, among which enterovirus 71 (EV-71) and Coxazivirus A16 (CoxA16) are the most common [4]. CoxA16 can be transmitted by fecal-oral route and close contact, easily causing outbreaks and epidemics in preschool children [5]. Since 1957, when the first HFMD case was reported in Toronto, HFMD has alternated or co-circulated with EV71, causing several pandemics worldwide [4-6]. In the past 20 years, HFMD has been prevalent in the Asia-Pacific region, including Singapore, Malaysia, Japan, South Korea, Thailand, Vietnam and Taiwan of China [7]. On May 2, 2008, HFMD was listed as a notifiable infectious disease in China.

China's statutory reporting system for infectious diseases features a passive monitoring network, which means under-reporting is inevitable. At the same time, some cases may not be seen in hospitals, so they cannot be captured. The limitations of such a passive monitoring may lead to incomplete reflection of the prevalence of HFMD in China with the existing monitoring data. It has been reported that $50 \%$ $80 \%$ of enterovirus infections are recessive infections with no or mild clinical symptoms, and only a few are manifested as dominant infections [8]. Serological investigation of the antibody levels of EV-A71 and CoxA16 in the population is the most effective way to indirectly reflect the prevalence of HFMD. In the meantime, it can be used to understand the dynamic changes of susceptibilities and immune levels of children at different age, so as to provide reference for the development of vaccination strategies and guide the prevention and control of HFMD.

A previous systematic review and meta-analysis has been conducted to evaluate the seroprevalence of enterovirus 71 antibody among children in China [9]. In this study, we retrospectively retrieved the published epidemiological literature on the seroprevalence of CoxA16 antibody, and the positive rates of CoxA16 antibody in different age groups have been comprehensively analyzed, so as to discuss the susceptibility of the population and the dynamic changes of immune status, and provide reference for the prevention and control of HFMD in the future.

\section{Materials and methods}

\section{Search strategy}

China National Knowledge Infrastructure (CNKI), WanFang Data, PubMed, EMbase, and the Cochrane Library to collect cross-sectional studies on the seroprevalence of CoxA16 antibody among people of various age groups from the date of their establishment to Jan. 2021 have been searched. The following keywords have been used in the literature search: "hand foot and mouth disease" OR "HFMD" OR "coxsackievirus A16" OR "CA16" OR "CoxA16") AND ("seroprevalence" OR "seroprevalent" OR "seronegative" OR "seropositive" OR "seroepidemiology" OR "seroepidemiological” OR "serologic" OR "serological” OR "antibody"). In addition, references of included literature have also been retrieved manually to avoid omission of relevant literature in the above-mentioned databases.

\section{Inclusion and exclusion criteria}

The inclusion criteria were as follows: (1) literature on the seroprevalence of CoxA16 antibody among people published by June 2020; (2) type of study: a crosssectional study that investigated the status of the seroprevalence of CoxA16 antibody; (3) positive rates of CoxA16 antibody can be calculated either explicitly or indirectly in the literature; (4) for repeated studies, the study with the largest sample size was selected. Exclusion criteria were as follows: (1) literature with obvious erroneous data or incomplete data; (2) types of research including review, conference, and other type of literature; (3) literature takes patients with hand foot and mouth disease as subjects.

\section{Literature screening and data extraction}

According to the inclusion criteria and exclusion criteria, two evaluators (PL and $\mathrm{YC}$ ) have made a preliminary screening by filtering the title and abstract of the literature. After excluding obviously irrelevant literature, full text has been further read to determine the final results for inclusion. Two researchers (PL and YC) have independently screened the literature, extracted and crosschecked the data. In case of differences in the data extraction, the third researcher (AT) assisted in the discussion and decision-making. The missing data have been supplemented by contacting the authors. We have extracted the following information from each eligible article: first author, publication date, survey area, sample size, seroprevalence of CoxA16 antibody, assay method, age range of the studied population, grouping factors.

\section{Quality assessment}

The included studies have been evaluated for bias risk in cross-sectional studies according to 11 evaluation criteria recommended by the Agency for Healthcare 
Research and Quality (AHRQ), and each item has been answered with "Yes (scored 1 point)", "No (scored 0 point)" or "Unclear (scored 0 point)" respectively [10]. The full score of quality evaluation is 11 points, with scores ranging from 0 to 3 points, from 4 to 7 points, and from 8 to 11 points representing low quality, medium quality and high quality, respectively.

\section{Statistical analysis}

The study has been conducted following the preferred reporting items for systematic reviews and meta-analysis (PRISMA) statement [11]. The pooled seroprevalence and $95 \%$ confidence interval $(\mathrm{CI})$ was the statistical effect size used to estimate the seroprevalence of CoxA16 antibody among people in different groups. Heterogeneity of the included studies has been determined by Cochran's Q test and the $\mathrm{I}^{2}$ statistic. If the Cochran's Q test was with $P<0.1$ and $\mathrm{I}^{2} \leq 50 \%$, indicating that there was no significant difference in the heterogeneity between studies, fixed-effect model was used for metaanalysis [12, 13], otherwise, random-effect model was adopted. Subgroup analysis by gender and age group have also been conducted in the meta-analysis. In addition, the stability of the meta-analysis results has been evaluated in the sensitivity analysis using studies that were excluded one by one. Finally, Begg's funnel plot and Egger's linear regression analysis have been used to evaluate publication bias [10]. All statistical analyses have been performed in the STATA 12.0 program (StataCorp LP, College Station, TX, USA). A $P$-value $<$ 0.05 was considered statistically significant.

\section{Results}

\section{Study search results}

The two authors of this study searched the relevant databases according to the retrieval strategy respectively, and a total of 229 relevant studies have been searched at the initial inspection. The inclusion criteria and exclusion criteria have been used to independently conduct study screening, and the results of data extraction and quality assessment have been compared. After deleting duplicates and screening according to the inclusion and exclusion criteria, a total of 14 studies that met the selection criteria have been included in this meta-analysis [14-27]. A total of 9562 samples have been investigated in 14 studies, among which 5682 had positive neutralizing antibodies against CoxA16, and the seroprevalence of the CoxA16 antibody ranged from 24.85 to $76.92 \%$. Out of the 14 studies, 5 articles were in Chinese and 9 in English. In addition, 3 medium-quality studies and 11 high-quality studies were included in the studies. The basic information of all studies included in this metaanalysis has been shown in Table 1. The detailed flow chart of article selection for inclusion and exclusion has been presented in Fig. 1.

\section{Seroprevalence of CoxA16 antibody}

Meta-analysis has been performed on the overall population and stratified based on different genders and age groups. A summary of the meta-analysis has been shown in Table 2. According to the heterogeneity test, significant heterogeneity was found among the studies, and the random-effect model has been used for metaanalysis. The results have showed that the seroprevalence of CoxA16 antibody was $56.3 \% \quad(95 \% \mathrm{CI}$ : $47.7 \% \sim 64.9 \%)$ in the overall population and $55.1 \%$ (95 \%CI: $44.1 \% \sim 66.1 \%$ ) in the Chinese population (Fig. 2). Subgroup analysis by gender has revealed that the seroprevalence of CoxA16 antibody was $56.1 \%$ (95 \%CI: $45.2 \% \sim 67.1 \%)$ in males and 60.0\% (95\%CI: $50.0 \% \sim 69.9 \%$ ) in females (Fig. S1 in supplemental materials). Subgroup analysis by age groups has revealed that the seroprevalence of CoxA16 antibody was $17.5 \%$ $(12.4 \% \sim 24.5 \%)$ in the $<1$ age group, $37.5 \%$ $(31.2 \% \sim 45.5 \%)$ in the $1 \sim 3$ age group, $50.8 \%$ (41.6\% 60.0\%) in the $4 \sim 5$ age group, $49.1 \%$ (95 \%CI: $36.2 \% \sim 62.0 \%)$ in the $0 \sim 5$ age group and $63.9 \%$ ( $95 \%$ CI: $53.1 \% \sim 74.7 \%$ ) in the over 5 age group (Fig. 3).

\section{Sensitivity analysis and publication bias}

A sensitivity analysis has been carried out by calculating the pooled seroprevalence of CoxA16 antibody of the remaining studies after excluding one study at a time. The results of the sensitivity analysis have showed that the meta-analysis results were stable. In addition, there was no evidence of publication bias in the current metaanalysis according to the Begg's funnel plots and Egger's linear regression test, the results have been shown in Table 2 (Fig. S2 and S3 in supplemental materials).

\section{Discussion}

CoxA16 virus is a common enterovirus that causes acute infection in children. It alternates or joins in prevalence with EV71 virus and is the main pathogen of HFMD. CoxA16 infection has become a major public health issue in the western pacific region due to its high transmission rate, especially in recent years [28]. Therefore, it is very important to carry out study on the determination of CoxA16 neutralizing antibody, so as to understand and predict the epidemic trend of HFMD and put forward prevention and control measures.

The present meta-analysis included 14 published studies containing a total of 9562 subjects, among which 5682 had positive neutralizing antibodies against CoxA16. The positive rate of CoxA16 neutralizing antibody in the serum of healthy people was relatively high with $56.3 \%$ (95 \%CI: $47.7 \% \sim 64.9 \%$ ) in the overall 


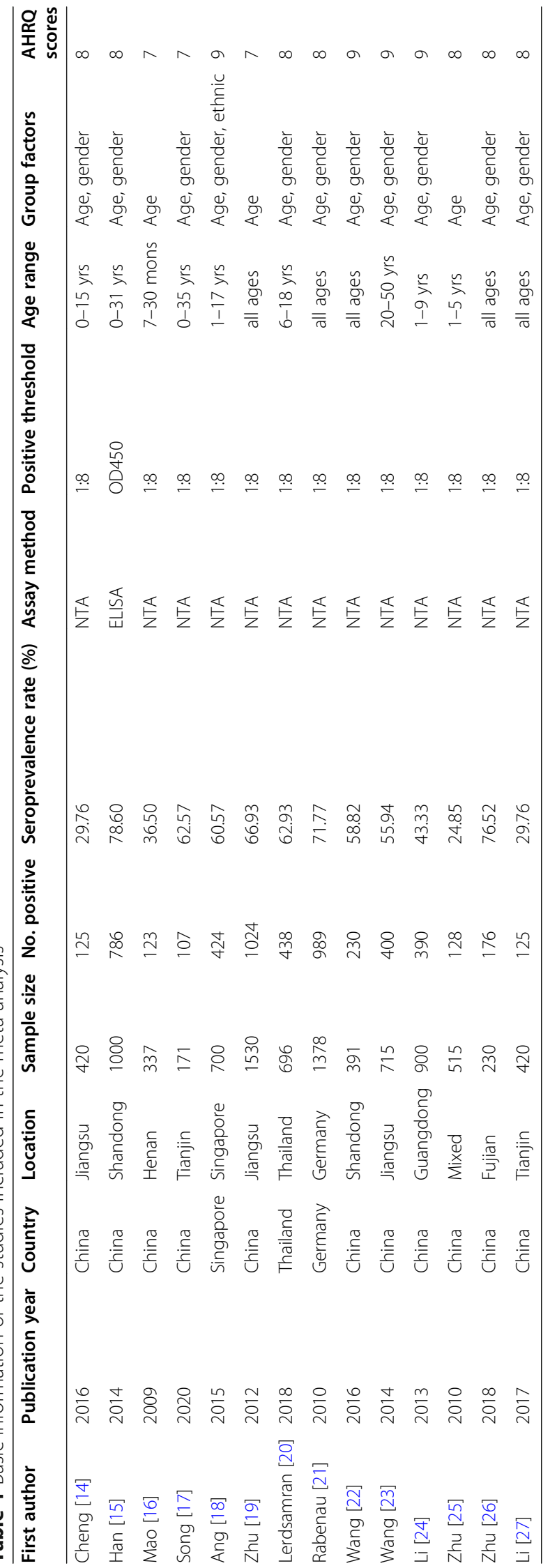




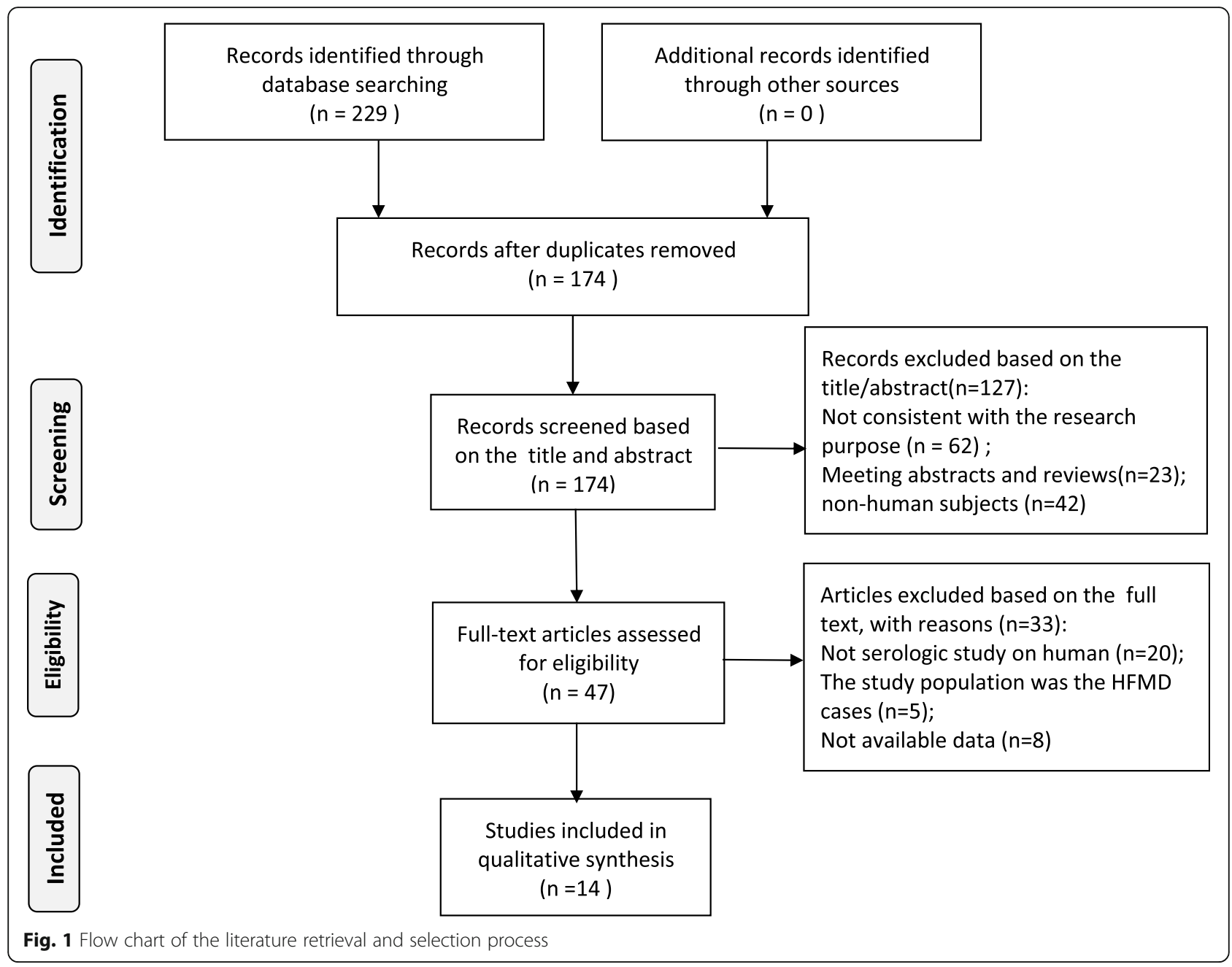

Table 2 Meta analysis results of the seroprevalence of CV-A16 (with $95 \%$ confidence interval) in people by ethnicity, gender and age group

\begin{tabular}{|c|c|c|c|c|c|c|c|}
\hline Group & Seroprevalence (\%) & $95 \% \mathrm{Cl}(\%)$ & Heterogeneity ( $P$-value) & $\mathrm{I}^{2}(\%)$ & Model & Begg's ( $P$-value) & Egger's ( $P$-value) \\
\hline \multicolumn{8}{|l|}{ Ethnicity } \\
\hline Overall & 56.3 & $47.7 \sim 64.9$ & $<0.001$ & 99.1 & Random & 0.228 & 0.105 \\
\hline Chinese & 55.1 & $44.1 \sim 66.1$ & $<0.001$ & 98.8 & Random & 0.335 & 0.156 \\
\hline Others & 61.0 & $58.8 \sim 63.2$ & 0.357 & 2.9 & Fixed & 0.224 & 0.135 \\
\hline \multicolumn{8}{|l|}{ Gender } \\
\hline Male & 56.1 & $45.2 \sim 67.1$ & $<0.001$ & 98.0 & Random & 0.436 & 0.213 \\
\hline Female & 60.0 & $50.0 \sim 69.9$ & $<0.001$ & 97.4 & Random & 0.640 & 0.202 \\
\hline \multicolumn{8}{|l|}{ Age } \\
\hline$<1 \mathrm{yrs}$ & 17.5 & $12.4 \sim 24.5$ & $<0.001$ & 88.6 & Random & 0.336 & 0.215 \\
\hline $1-3$ yrs & 37.5 & $31.2 \sim 45.5$ & $<0.001$ & 92.3 & Random & 0.569 & 0.425 \\
\hline $4-5 y r s$ & 50.8 & $41.6 \sim 60.0$ & $<0.001$ & 87.6 & Random & 0.758 & 0.628 \\
\hline $0 \sim 5$ yrs & 49.1 & $36.2 \sim 62.0$ & $<0.001$ & 98.4 & Random & 0.837 & 0.266 \\
\hline$>5 \mathrm{yrs}$ & 63.9 & $53.1 \sim 74.7$ & $<0.001$ & 98.8 & Random & 0.115 & 0.380 \\
\hline
\end{tabular}




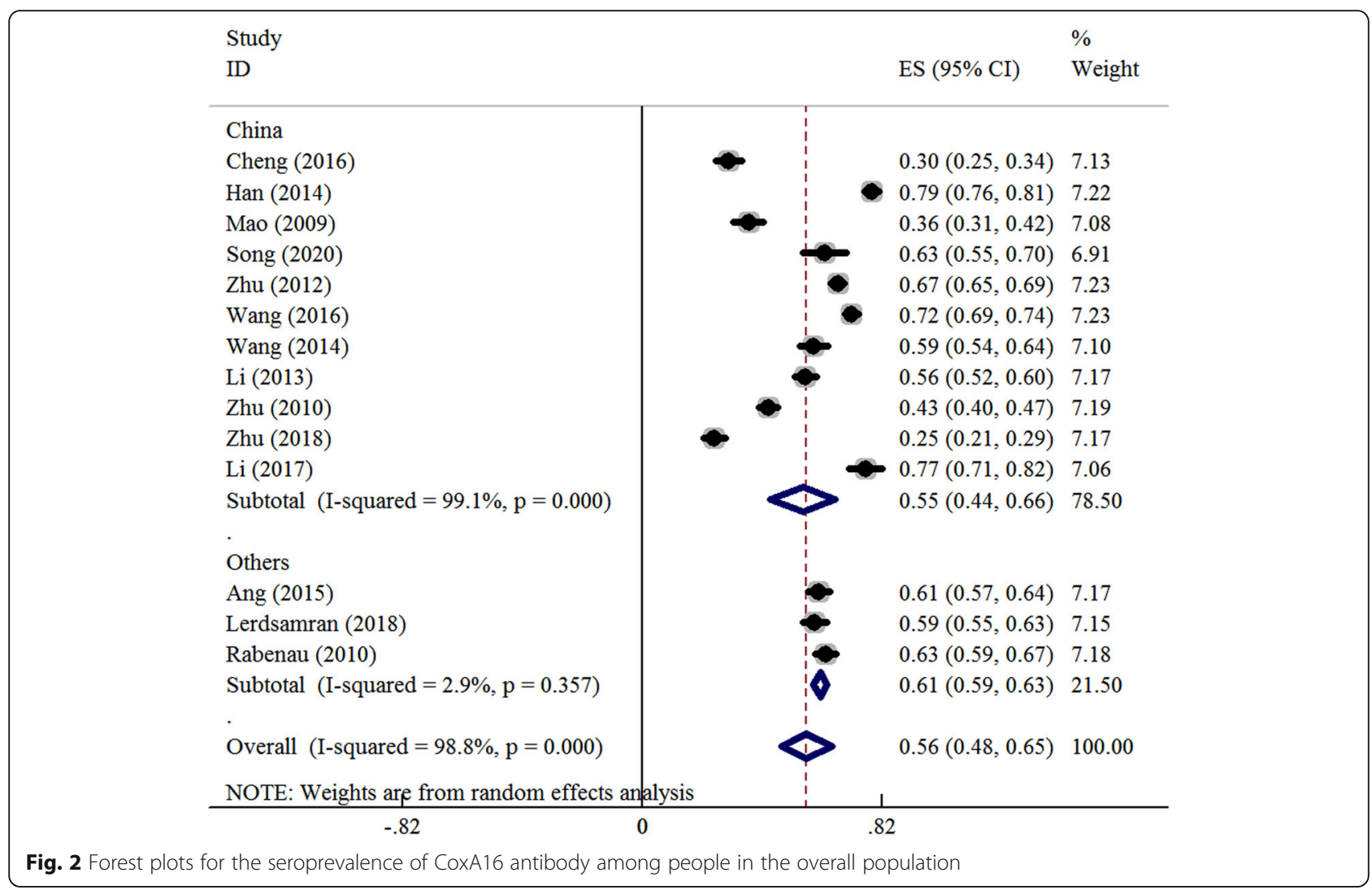

population and $55.1 \%$ (95 \%CI: $44.1 \% \sim 66.1 \%$ ) in the Chinese population. The meta-analysis also showed that the positive rate of CoxA16 neutralizing antibody was slightly higher in females than in males. This result was consistent with previous studies conducted in China, Singapore and Germany [17, 18, 21].
The meta-analysis also showed that the positive rate of CoxA16 antibody increased gradually from 1 to 5 years old and remained at a high level after 5 years old. Unfortunately, the positive rate of CoxA16 neutralizing antibodies was not analyzed for infants under 12 months of age. Studies have shown that with the natural attenuation of

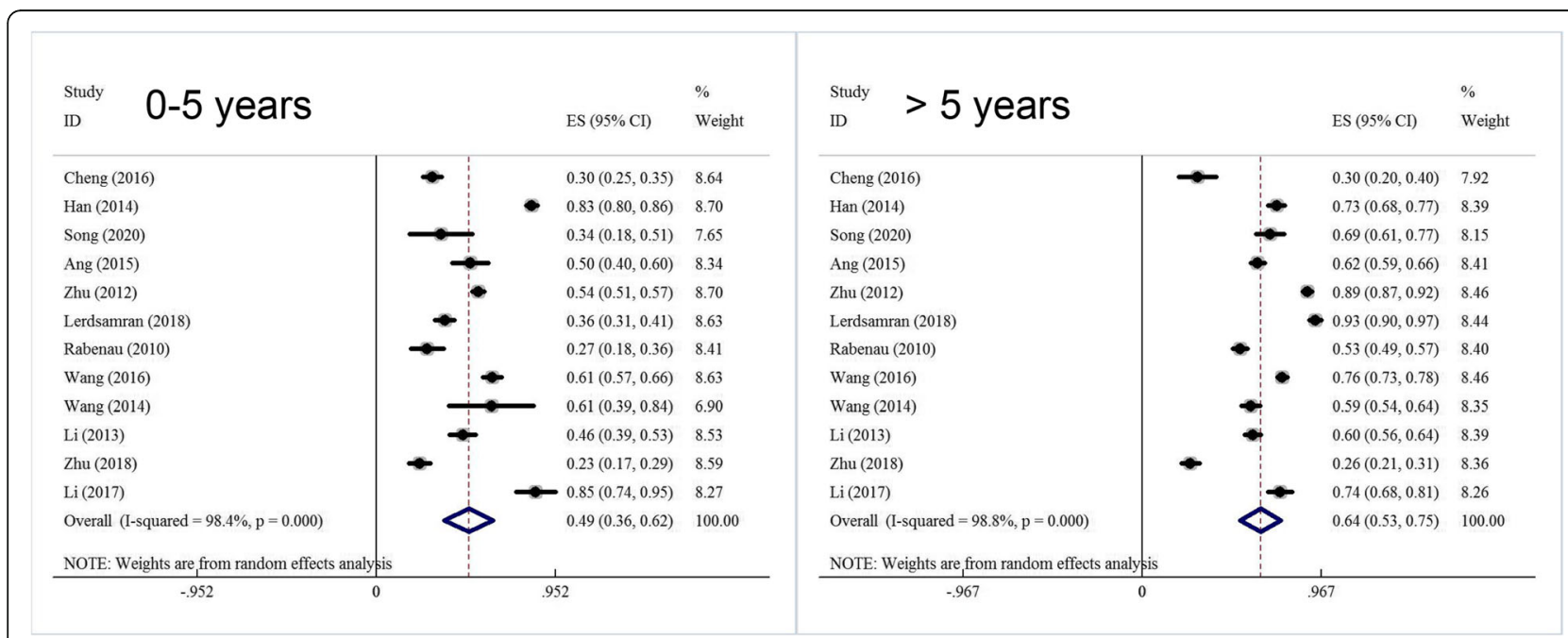

Fig. 3 Forest plots for the seroprevalence of CoxA16 antibody among people in different age groups 
mother-to-child antibody, the antibody level of newborns decreased gradually from birth to the first year of life. A mother-newborn matching study in Jiangsu, China, found that the average maternal antibody positive rate at birth was $90 \%$, higher than EV-A71 infection level. However, the antibody level attenuated rapidly in infants of $0 \sim 12$ months, which was similar to the change trend of EV-A71. After 1 year of age, antibody levels gradually increased with time due to increased exposure opportunities [19].

A retrospective study of the seroepidemiology of antibodies against EV71 and CoxA16 in prenatal women and their infants conducted by Mao et al. showed that the level of maternal antibody titers decreased dramatically during the first 7 months and remained at a relatively low level thereafter [16]. During the period of 4 6 years old, children began to study in kindergartens and live together with others, which may lead to increased exposure and infection opportunities of enterovirus and more likely to get and spread HFMD. After that period, children's antibody level to enterovirus will gradually rise. Rabenau et al. found that the positive rate of CoxA16 neutralizing antibody in German children increased from $27 \%$ in $1-4$ years old to $52 \%$ in 5-9 years old [21]. The present meta-analysis showed that CoxA16 antibody levels were significantly higher in children over 5 years of age than in children under 5 years old.

There are some limitations in this meta-analysis. Firstly, there was considerable heterogeneity in this meta-analysis, the causes may relate to the study area, the age range of the study population, the sampling time of objects in the studies and other factors. Due to the insufficient information provided in the original literature, subgroup analysis and meta-regression analysis cannot be carried out further. Secondly, the included literature was mainly from China, and the included regions are not evenly distributed, so the meta-analysis results may not reflect the positive rate of CoxA16 neutralizing antibody in the whole population. Finally, only English and Chinese literatures were included in this meta-analysis, so language bias may exist in this study.

\section{Conclusions}

In summary, this meta-analysis showed that the proportion of CoxA16 virus infected population is relatively large, among which the CoxA16 positive rate is the lowest among people under 5 years old. The newborns' level of CoxA16 neutralizing antibody from mothers is limited, and given there is no efficient vaccine specifically for this so far, the key to control the CoxA16 epidemic lays in prevention and control of children under 5 years old. In the future, public health departments should strengthen the publicity, education and prevention guidance on the prevention and control of HFMD, and urge parents to take personal protection for infants and young children.

\section{Abbreviations}

HFMD: Hand foot and mouth disease; CoxA16: Coxsackie virus group A type 16; EV-71: Enterovirus 71; AHRQ: Agency for Healthcare Research and Quality; PRISMA: Preferred reporting items for systematic reviews and meta-analysis; 95\% Cl: 95\% confidence interval

\section{Supplementary Information}

The online version contains supplementary material available at https://doi. org/10.1186/s13690-021-00688-z.

Additional file 1: Figure S1. Forest plots for the seroprevalence of CoxA16 antibody among people in different genders.

Additional file 2: Figure S2. Sensitive analysis for the seroprevalence of CoxA16 antibody among people in the overall population.

Additional file 3: Figure S3. Begg's funnel plot for the seroprevalence of CoxA16 antibody among people in the overall population.

Additional file 4: Table 1. The search strategy of seroprevalence of CoxA16 antibody among people.

\section{Acknowledgements}

Not applicable.

\section{Authors' contributions}

$\mathrm{PL}$ and FG participated in the design of the study and performed the statistical analysis, YC and AT performed the data extraction and statistical analysis, and JBY participated in its design and coordination and helped to revise the manuscript. All authors read and approved the final manuscript.

\section{Funding}

This work was supported by Zhoushan Science and Technology Project (2017C31125, 2018C31118, 2017B02).

\section{Availability of data and materials}

The datasets used and/or analysed during the current study are available from the corresponding author on reasonable request.

\section{Declarations}

Ethics approval and consent to participate Not applicable.

Consent for publication

Not applicable.

\section{Competing interests}

The authors declare that they have no competing interests.

Received: 27 April 2021 Accepted: 7 September 2021

Published online: 17 September 2021

\section{References}

1. Chang ZR, Zhang J, Sun JL, Zhang WD, Wang ZJ. Epidemiological features of hand, foot and mouth disease in China, 2008-2009. Zhonghua Liu Xing Bing Xue Za Zhi. 2011;32(7):676-80.

2. Wang XF, Lu J, Liu XX, Dai T. Epidemiological features of hand, foot and mouth disease outbreaks among Chinese preschool children: a metaanalysis. Iran J Public Health. 2018;47(9):1234-43.

3. Cai K, Wang Y, Guo Z, Yu H, Li H, Zhang L, Xu S, Zhang Q. Clinical characteristics and managements of severe hand, foot and mouth disease caused by enterovirus A71 and coxsackievirus A16 in Shanghai, China. BMC Infect Dis. 2019;19(1):285. https://doi.org/10.1186/s12879-019-3878-6.

4. Ji H, Fan H, Lu PX, Zhang XF, Ai J, Shi C, et al. Surveillance for severe hand, foot, and mouth disease from 2009 to 2015 in Jiangsu province: epidemiology,etiology, and disease burden. BMC Infect Dis. 2019;19(1):79. https://doi.org/10.1186/s12879-018-3659-7.

5. Fan X, Jiang J, Liu Y, Huang X, Wang $P$, Liu L, Wang J, Chen W, Wu W, Xu B. Detection of human enterovirus 71 and Coxsackievirus A16 in an outbreak 
of hand, foot, and mouth disease in Henan Province, China in 2009. Virus Genes. 2013;46(1):1-9.

6. Noisumdaeng P, Sangsiriwut K, Prasertsopon J, Klinmalai C, Payungporn S, Mungaomklang A. Complete genome analysis demonstrates multiple introductions of enterovirus 71 and coxsackievirus A16recombinant strains into Thailand during the past decade. Emerg Microbes Infect. 2018;7(1):21420.

7. Puenpa J, Wanlapakorn N, Vongpunsawad S, Poovorawan $\mathrm{Y}$. The history of enterovirus A71 outbreaks and molecular epidemiology in the Asia-Pacific Region. J Biomed Sci. 2019;26(1):75. https://doi.org/10.1186/s12929-0190573-2.

8. Deng AP, Zhang YH, Sun LM, Zeng HR, Li W, Ke CW, et al. Survey on the recessive infection of pathogen to hand-foot-mouth disease among healthy adults and children in Guangdong province. Zhonghua Liu Xing Bing Xue Za Zhi. 2012;33(2):189-91.

9. Yang B, Wu P, Wu JT, Lau EH, Leung GM, Yu H, Cowling BJ. Seroprevalence of enterovirus 71 antibody among children in china: a systematic review and meta-analysis. Pediatr Infect Dis J. 2015;34(12):1399-406.

10. Fang Y, Wang S, Zhang L, Guo Z, Huang Z, Tu C, Zhu BP. Risk factors of severe hand, foot and mouth disease: a meta-analysis. Scand I Infect Dis. 2014:46(7):515-22.

11. Shamseer $L$, Moher $D$, Clarke $M$, et al. Preferred reporting items for systematic review and metaanalysis protocols (PRISMA-P) 2015: elaboration and explanation. BMJ. 2015;349:97647.

12. Higgins JP, Thompson SG, Deeks JJ, Altman DG. Measuring inconsistency in meta-analyses. BMJ. 2003;327:557-60.

13. Hedges LV, Vevea JL. Fixed-and random-effects models in meta-analysis. Psychol Methods. 1998;3:486-504.

14. Cheng C, Pang HY. Seroepidemiologic investigation of enterovirus CA16 among children in Donghai County. Chin J School Doctor. 2016;30(6):454-6.

15. Han XY, Pan J, Liu LZ, Yang GL, Guan HY, Wang CR. Serological investigation on hand foot and mouth disease in healthy population in Jinan. Chin J Health Lab. 2014;24(6):877-8.

16. Mao QY, Yang ZW, Yu X, et al. Epidemic tendency of neutralizing antibody against Enterovirus 71 and Coxsackievirus A 16 in Infants in Rural Area of Kaifeng City, Henan Province,China. Chin J Biologicals. 2009;22(9):911-3.

17. Song D. Serological survey of hand, foot and mouth disease among healthy people in Hebei District, Tianjin City. 2016 2019 Medical Information. 2020;33(8):147-9.

18. Ang LW, Tay J, Phoon MC, Hsu JP, Cutter J, James L, Goh KT, Chow VT. Seroepidemiology of Coxsackievirus A6, Coxsackievirus A16, and Enterovirus 71 infections among children and adolescents in Singapore, 2008-2010. PLoS One. 2015;10(5):e0127999.

19. Zhu FC, Liang ZL, Meng FY, Zeng Y, Mao QY, Chu K, et al. Retrospective study of the incidence of HFMD and seroepidemiology of antibodies against EV71 and CoxA16 in prenatal women and their infants. PLoS One. 2012;7(5):e37206.

20. Lerdsamran H, Prasertsopon J, Mungaomklang A, Klinmalai C, Noisumdaeng P, Sangsiriwut K, Tassaneetrithep B, Guntapong R, et al. Seroprevalence of antibodies to enterovirus 71 and coxsackievirus A16 among people of various age groups in a northeast province of Thailand. Virol J. 2018;15(1): 158-62.

21. Rabenau HF, Richter M, Doerr HW. Hand, foot and mouth disease: seroprevalence of Coxsackie A16 and Enterovirus 71 in Germany. Med Microbiol Immunol. 2010:199(1):45-51.

22. Wang JX, Zhu SL, Wang J, Lin Y, Pei YW, Sun DP, Zhang Y, et al. Seroprevalence of Enterovirus A71 and Coxsackievirus A16 in Healthy People in Shandong Province, China. PLoS One. 2016;11(9):e0162373.

23. Wang $X$, Xing $M$, Zhang $C$, Yang $Y$, Chi Y, Tang X, Zhang H, Xiong S, Yu L, Zhou D. Neutralizing antibody responses to enterovirus and adenovirus in healthy adults in China. Emerg Microbes Infect. 2014;3(5):e30. https://doi. org/10.1038/emi.2014.30

24. Li W, Yi L, Su J, Lu J, Ke C, Zeng H, Guan D, Ma C, Zhang W, Xiao H, Li H, Lin J, Zhang Y. Seroprevalence of human enterovirus 71 and coxsackievirus A16 in Guangdong, China, in pre- and post-2010 HFMD epidemic period. PLoS One. 2013:8(12):e80515.

25. Zhu R, Cheng T, Yin Z, Liu D, Xu L, Li Y, Wang W, Liu J, Que Y, Ye X, Tang Q, Zhao Q, Ge S, He S, Xia N. Serological survey of neutralizing antibodies to eight major enteroviruses among healthy population. Emerg Microbes Infect. 2018:7(1):215-21.
26. Zhu Z, Zhu S, Guo X, Wang J, Wang D, Yan D, Tan X, Tang L, et al. Retrospective seroepidemiology indicated that human enterovirus 71 and coxsackievirus A16 circulated wildly in central and southern China before large-scale outbreaks from 2008. Virol J. 2010;7:300. https://doi.org/10.1186/1 743-422X-7-300

27. Li P, Chen YM, Wang HL, Wei PN. Survey of neutralizing antibodies against EV71 and Cox A16 in healthy population in Wuqing district, Tianjin. Dis Surveillance. 2017;32(7):573-5.

28. Mao Q, Wang Y, Yao X, Bian L, Wu X, Xu M, Liang Z. Coxsackievirus A16: epidemiology, diagnosis, and vaccine. Hum Vaccin Immunother. 2014;10(2): $360-7$.

\section{Publisher's Note}

Springer Nature remains neutral with regard to jurisdictional claims in published maps and institutional affiliations.
Ready to submit your research? Choose BMC and benefit from:

- fast, convenient online submission

- thorough peer review by experienced researchers in your field

- rapid publication on acceptance

- support for research data, including large and complex data types

- gold Open Access which fosters wider collaboration and increased citations

- maximum visibility for your research: over $100 \mathrm{M}$ website views per year

At BMC, research is always in progress.

Learn more biomedcentral.com/submissions 